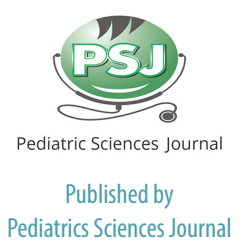

Pediatrics Sciences Journal

\section{Case distribution and survival rate in Pediatric Intensive Care Unit (PICU) at Banjarmasin, Indonesia}

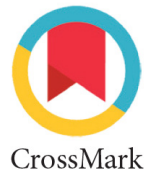

\author{
Choirul Anam ${ }^{1 *}$, Niarsari Anugrahing Putri', \\ Rahmad Ramadhani ${ }^{1}$, Yasmin Musfirah ${ }^{1}$
}

'Department of Pediatrics, Ulin Hospital, Banjarmasin, South Borneo, Indonesia

*Corresponding to:

Choirul Anam; Department of Pediatrics,

Ulin Hospital, Banjarmasin, South

Borneo, Indonesia;

anam dr86@yahoo.com

Received: 2021-10-21

Accepted: 2021-12-02

Published: 2021-12-10

\section{ABSTRACT}

Introduction: Epidemiological studies about case distribution and survival in PICU is important to do. Knowledge of these epidemiological studies can assist in decision-making to improve patient quality of care. So far there is no data about the case distribution and survival rate of the patients in the PICU in Banjarmasin, Indonesia. This study aims to provide an overview of case distribution and survival rates of patients treated at the PICU of Ulin Hospital Banjarmasin.

Methods: A retrospective study was conducted at the PICU of Ulin Hospital Banjarmasin. Data was taken from patients' records from January 2017 to December 2018.

Results: A total of 202 patients were admitted to the PICU, males 109 and females 93 . The mortality rate was $17 \%$ with a survival rate, $83 \%$ with a mean length of stay of 10 days. The most common patient diagnosis was pneumonia $23 \%$, meningoencephalitis $10 \%$, and dengue shock syndrome $6 \%$. The system commonly involved was respiratory system $26 \%$, central nervous system $17 \%$, and infection 13\%. The median length of stay for overall admission was 9 days with a mean of 10 days. The cardiovascular and respiratory systems tend to have lower survival rates, $78 \%$, and $79 \%$ respectively.

Conclusions: This study shows that respiratory, neurological, and infectious diseases are the most common diseases that cause children to be admitted to the PICU. The mortality rate in this study was $17 \%$ with a mean length of stay of 10 days. It is necessary to focus on medical facilities and interventions to reduce respiratory-related mortality.

Keywords: Case distribution, cause of death, epidemiological studies, PICU.

Cite This Article: Anam, C., Putri, N.A., Ramadhani, R., Musfirah, Y. 2021. Screening for congenital hypothyroidism in Malang, East Java in 2020. Pediatrics Sciences Journal 2(2): 44-47.

\section{INTRODUCTION}

The pediatric intensive care unit (PICU) is a specialized unit designed primarily to provide qualified care for critically ill children that extends beyond its walls to include emergency department, wards, and prehospital settings. Epidemiological studies that focused on case distribution and survival in PICU are important to do. Knowledge of epidemiological reports concerning the case distribution and mortality of a health care unit can assist in strategic decisions aimed at improving patient quality of care. There are many studies documenting case distribution and outcome of PICU from western countries but very few such studies are available from the developing countries. ${ }^{1-3}$

Studies in the United Kingdom by Brooten et al on 2016 reports that patients treated in the PICU mostly suffer cardiovascular disease followed by respiratory and neurological. However, respiratory disease is the cause most frequent for treatment in the PICU room. In Ethiopia, the most common cause of admission is septic shock and severe sepsis or multiorgan failure was the leading cause of death following respiratory failure, brain herniation, and cardiac arrest. The patient survival rate in PICU around the world is about $75 \%$ per year, while the patient survival rate at PICU in America is approximately $80 \%$ of patients. So far there is no data about the case distribution and survival rate of the patients in the PICU in Banjarmasin, Indonesia. This study objective is to provide an overview of the case distribution and the survival rate of patients treated at the PICU RSUD Ulin Banjarmasin. ${ }^{4-6}$

\section{METHODS}

\section{Study Design}

This research is a retrospective descriptive study that falls into observational research and cross-sectional research category. This research employs an approach namely qualitative analysis.

\section{Sample collection and characteristics}

The research populations were taken from the PICU of Ulin Hospital Banjarmasin, South Borneo, Indonesia. Patients that were taken as samples aged more than 28 days to 18 years old and had complete data recorded.

\section{Data collection and analysis}

The data collected in this study was secondary data. Data was taken from patients records during the study period 
January 2017 until December 2018. The data analyses are done by using univariate analysis which showed in the form of frequency tables.

\section{RESULTS}

During January 2017 to December 2018, a total of 202 patients were admitted to the PICU. The majority was male 109 and 93 were females. The mortality rate was $17 \%$ with a survival rate of $83 \%$ with a mean length of stay of 10 days (Table 1 ).

The most common patient diagnosis in this study was pneumonia $23 \%$, meningoencephalitis $10 \%$, and dengue shock syndrome $6 \%$ (Table 2). The system commonly involved was central nervous system $17 \%$, respiratory system $26 \%$, and other common causes were infection $13 \%$.

In this study, the mortality rate was $17 \%$ with characteristics shown in Table 3. The majority were male, the mean length of stay was 10 days, and the most common disease was pneumonia.

The median length of stay for overall admission was 9 days with a mean of 10 days. There are six patients (3\%) that had prolonged length of stay ( $>28$ days). Patient with allergy and immunology, nephrology, and endocrine disease had a longer mean length of stay. From the system involved, cardiovascular and respiratory tend to have lower survival rates, $78 \%$, and $79 \%$ respectively (Table 4).

Among 202 patients (Table 5), 57 patients had thrombocytopaenia incidence of $28.2 \%$. Dengue infection was the most common disease $(35 \%)$ while the other thrombocytopenia's were sepsis (22.8\%), central nervous system infection (19.3\%), haematology disorder (12.2\%), others (10.7\%). Among 34 death patients, 8 patients had thrombocytopenia (23.5\%).

C-Reactive Protein (CRP) was checked to 53 patients, $90 \%$ had result above the cut-off point (>10 mg/ l). Sepsis (60.4\%) was the most common disease (96.7\%), while other were pneumonia (18.7\%), dengue infection (14.6\%), and noninfection (6.3\%). The mortality rate was higher in patients who had an increase in CRP (38.7\%).

\section{DISCUSSION}

During the study period, 202 children were admitted to the PICU department,

\section{Table 1. Sample characteristic}

\begin{tabular}{lc}
\multicolumn{1}{c}{ Sample } & N (\%) \\
\hline Gender & \\
Male & $109(54)$ \\
Female & $93(46)$ \\
Outcome & \\
Survived & $168(83)$ \\
Death & $34(17)$ \\
Length of stay (mean \pm SD) & $10( \pm 7)$ \\
\hline
\end{tabular}

Table 2. Patient Diagnosis

\begin{tabular}{lc}
\hline \multicolumn{1}{c}{ Diagnosis } & $\mathbf{n}(\%)$ \\
\hline Pneumonia & $47(23)$ \\
Meningoencephalitis & $21(10)$ \\
Dengue Shock Syndrome & $12(6)$ \\
Dengue Fever & $8(4)$ \\
Acute Kidney Injury & $6(2)$ \\
Anemia gravis & $10(5)$ \\
Sepsis & $7(3)$ \\
Chronic Kidney Disease & $5(1)$ \\
Others & $86(42)$ \\
\hline
\end{tabular}

Table 3. Mortality characteristic

\begin{tabular}{lc}
\multicolumn{1}{c}{ Sample } & N (\%) \\
\hline Gender & \\
Male & $19(56)$ \\
$\quad$ Female & $15(44)$ \\
Length of stay (mean \pm SD) & $10( \pm 5,2)$ \\
\hline
\end{tabular}

Table 4. Distribution in relation to the system involved

\begin{tabular}{lccc}
\hline \multicolumn{1}{c}{ System involved } & $\begin{array}{c}\text { Length of stay days } \\
\text { (mean) }\end{array}$ & $\begin{array}{c}\text { Survival rate } \\
\text { (\%) }\end{array}$ & Death rate (\%) \\
\hline Allergic and immunology & $58(19)$ & 100 & 0 \\
Endocrine & $59(14)$ & 100 & 0 \\
Gastrohepatology disorder & $86(6)$ & 85 & 15 \\
Hematology and oncology & $273(10)$ & 81 & 19 \\
disorder & & & \\
Infection & $277(10)$ & 82 & 18 \\
Cardiovascular & $87(9)$ & 78 & 22 \\
Nephrological & $154(14)$ & 82 & 18 \\
Neurological & $713(13)$ & 87 & 13 \\
Respiratory & $414(8)$ & 79 & 21 \\
\hline
\end{tabular}

with the majority of males $54 \%$ than $46 \%$ females, this is in line with the study of Sahoo et al. In India. ${ }^{7}$ This study shows that respiratory, neurological, and infectious diseases are the most common diseases that cause children to be admitted to the PICU. This is similar to Shah S et al study, which reported that respiratory emergency was the biggest indication for admission to the PICU. ${ }^{8}$ Other studies have also stated that respiratory disease is the most common cause of patients being treated in intensive care units. ${ }^{2}$

The mortality rate for this study was $17 \%$ with a mean length of stay of 10 days. Another study by El Halal et al showed a higher mortality rate $(11.9 \%)$ in patients treated for more than seven days. ${ }^{9}$ The 
Table 5. Disease in thrombocytopenic and non-thrombocytopenic

\begin{tabular}{lcc}
\hline \multicolumn{1}{c}{ Disease } & Thrombocytopenic & Non-thrombocytopenic \\
& $\mathbf{N}(\%)$ & $\mathbf{N}(\%)$ \\
\hline Dengue Infection & $20(35)$ & $0(0)$ \\
Sepsis & $13(22.8)$ & $10(10.3)$ \\
Central Nervous system disorder & $11(19.3)$ & $47(32.4)$ \\
Hematology Disorder & $7(12.2)$ & $13(8.9)$ \\
Others & $6(10.5)$ & $77(47.6)$ \\
\hline
\end{tabular}

Table 6. Disease in increase of CRP

\begin{tabular}{lcc}
\hline \multicolumn{1}{c}{ Disease } & $\begin{array}{c}\text { CRP } \geq \mathbf{1 0} \text { g/l } \\
\mathbf{n}(\%)\end{array}$ & $\begin{array}{c}\text { CRP }<\mathbf{1 0} \text { g/l } \\
\mathbf{n}(\%)\end{array}$ \\
\hline Sepsis & $29(96.7)$ & $1(3.3)$ \\
Pneumonia & $9(75)$ & $3(25)$ \\
Dengue Infection & $6(100)$ & $0(0)$ \\
Non-Infection & $3(75)$ & $1(25)$ \\
\hline
\end{tabular}

ICU mortality rate varies depending on the case, age, length of stay, and patient comorbidities. ${ }^{10}$ Other data from India shows a $10.5 \%$ mortality rate. Important factors that influence the recovery of patients include human resources, adequate equipment, and continuous medical education from the institution. ${ }^{11}$

The most common cause of death was pneumonia (32\%). This is in line with a study in India by Divecha et al, where pneumonia contributed to $66.89 \%$ of PICU hospitalizations and 91\% of deaths. From this study it was also stated that one third of patients did not receive complete immunization and were malnourished, so this situation could increase the severity of infection and increase mortality. ${ }^{12}$

Length of stay in PICU is a marker of illness severity, resource utilization, and performance. International studies had described small PICU with long stay patients $1-7,5 \%$ of the total PICU population. ${ }^{13}$ In our study, support these findings with $3 \%$ long stay patient. From a study in India, the mean duration of stay in PICU was $3.2 \pm 4.5$ days, which is similar to the records of Haque and Bano1 in Pakistan, but in contrast, a mean duration of $4.52 \pm 2.6$ days was reported by Khilnani et al. ${ }^{11}$ In our study, the median length of stay was longer to 9 days.

Low survival rate in cardiovascular and respiratory was also observed in Volakli et al and Singhal et al with respiratory condition was the most common cause of death. ${ }^{14,15}$ Cardiovascular disease in our study was congenital heart disease (CHD) consistent with Gundogdu et al. reported that in PICU nearly half of all mortality caused by CHD occurred during infancy. ${ }^{16}$

This study shows the incidence of thrombocytopaenia was $28.2 \%$ which is lower than study by Kaur et al. and Yilmaz et al. where their incidence was $32.4 \%$ and $59.7 \%$ respectively. ${ }^{17,18}$ While our study was higher than the study by Agarwa et al., i.e. $25 \%{ }^{19}$ This difference may be because other studies had smaller total samples and shorter duration of time.

Our study shows increase of CRP above the cut-off point was $90 \%$ of 53 patients, which was sepsis as the most common disease. Similar to a study by Fatima et al where $95.6 \%$ of sepsis patients had increased CRP. ${ }^{20}$ Total mortality in our patient was $38.7 \%$, similar to study by Sharma et.al had mortality rate $37.6 \%$. Other studies done previously by Horvat et.al and Lubis et.al was $21.7 \%$ and $55.7 \%$ respectively. ${ }^{21-23}$

From this study, the respiratory disease was the most common disease for patients admitted to PICU and was the most common cause of death. Based on this data, it is necessary to focus on medical facilities and interventions such as immunization, improving nutrition, education about the dangers of disease and anaemia therapy for strategies to reduce respiratory-related mortality, and children under one year of age with respiratory diseases to receive the early intervention because the risk of death is higher based on previous reports.

A potential limitation of our study related to the sample size and population we used may not be representative of the whole region and limit our ability to transfer our findings to other regional hospitals and countries because all patients participating in this study were from Ulin Hospital Banjarmasin. However, this study might be used as a reference for future studies.

\section{CONCLUSIONS}

This study shows that respiratory, neurological, and infectious diseases are the most common diseases that cause children to be admitted to the PICU. The mortality rate in this study was $17 \%$ with a mean length of stay of 10 days. Respiratory disease was the most common disease for patients admitted to PICU and was the most common cause of death. Thrombocyte level and CRP might be used as mortality predictors. Based on these findings, it is necessary to focus on medical facilities and interventions to reduce respiratory-related mortality.

\section{ACKNOWLEDGEMENTS}

Authors would like to thank Head of Department of pediatrics and principal of the medical college for providing the facilities to carry out this research work.

\section{CONFLICT OF INTEREST}

None declared.

\section{ETHICAL CONSIDERATION}

Ethical approval has been approved by ethical committee for study of Ulin Hospital Banjarmasin.

\section{FUNDING}

No funding sources.

\section{AUTHOR CONTRIBUTION}

All authors equally contribute to the study from the conceptual framework, data acquisition, data analysis until interpreting the study results through publication. 


\section{REFERENCES}

1. Turner EL, Nielsen KR, Jamal SM, von Saint André-von Arnim A, Musa NL. A Review of Pediatric Critical Care in Resource-Limited Settings: A Look at Past, Present, and Future Directions. Front Pediatr. 2016;4:5.

2. Lanetzki CS, de Oliveira CAC, Bass LM, Abramovici S, Troster EJ. The epidemiological profile of Pediatric Intensive Care Center at Hospital Israelita Albert Einstein. Einstein (Sao Paulo). 2012;10:16-21.

3. Abdelatif RG, Mohammed MM, Mahmoud RA, Bakheet MAM, Gima M, Nakagawa S. Characterization and Outcome of Two Pediatric Intensive Care Units with Different Resources. Crit Care Res Pract. 2020;2020.

4. Brooten D, Youngblut JM, Caicedo C, Seagrave L, Cantwell GP, Totapally B. Cause of Death of Infants and Children in the Intensive Care Unit: Parents' Recall vs Chart Review. Am J Crit care an Off Publ Am Assoc Crit Nurses. 2016;25:235-42.

5. Hajari S, Sawitri E, Muhyi A, Nugroho H. Gambaran Mortalitas Pasien Di Ruang Picu Rsud Abdul Wahab Sjahranie Samarinda Periode 2016-2017. J Kebidanan Mutiara Mahakam. 2019;7:41-57.

6. Burns JP, Sellers DE, Meyer EC, Lewis-Newby M, Truog RD. Epidemiology of death in the PICU at five U.S. teaching hospitals*. Crit Care Med. 2014;42:2101-8.

7. Sahoo B, Patnaik S, Mishra R, Jain M. Morbidity pattern and outcome of children admitted to a paediatric intensive care unit of Eastern India. Int J Contemp Pediatr. 2017;4:486.

8. Shah G. Admission Patterns and Outcome in a Pediatric Intensive Care Unit in Nepal. Br J Med Med Res. 2014;4:4939-45.
9. El Halal MGDS, Barbieri E, Filho RM, Trotta E de A, Carvalho PRA. Admission source and mortality in a pediatric intensive care unit. Indian J Crit care Med peer-reviewed, Off Publ Indian Soc Crit Care Med. 2012;16:81-6.

10. Desikan S, Bray B, Kurian J, Ali S, Chappel W. Outcome after ICU admission in patients over ninety years old. Anesthesiology. 2007;107.

11. Abhulimhen-Iyoha BI, Pooboni SK, Vuppali NKK. Morbidity Pattern and Outcome of Patients Admitted into a Pediatric Intensive Care Unit in India. Indian J Clin Med. 2014;5:IJCM.S13902.

12. Divecha C, Tullu MS, Chaudhary S. Burden of respiratory illnesses in pediatric intensive care unit and predictors of mortality: Experience from a low resource country. Pediatr Pulmonol. 2019;54:1234-41.

13. Nupen TL, Argent AC, Morrow B. Characteristics and outcome of long-stay patients in a paediatric intensive care unit in Cape Town, South Africa. S Afr Med J. 2016;107:70-5.

14. Volakli E, Sdougka M, Tamiolaki M, Tsonidis C, Reizoglou M, Giala M. Demographic profile and outcome analysis of pediatric intensive care patients. Hippokratia. 2011;15:316-22.

15. Singhal D, Kumar N, Puliyel JM, Singh SK, Srinivas V. Prediction of mortality by application of PRISM score in intensive care unit. Indian Pediatr. 2001;38:714-9.

16. Gundogdu Z, Babaoglu K, Deveci M, Tugral O, Zs U. A Study of Mortality in Cardiac Patients in a Pediatric Intensive Care Unit. Cureus. 2019;11:e6052.

17. Kaur A, Sethi GK, Goyal RK, Kaur A, Kaur R, Dhir SK, et al. Thrombocytopenia in Paediatric ICU: Incidence, Transfusion Requirement and
Role as Prognostic Indicator. J Clin Diagn Res. 2015;9:SC05-7.

18. Yilmaz S, Yildizdas D, Acipayam C, Bayram I, Ozcan N, Horoz OO, et al. The effect of Thrombocytopenia on outcome in critically ill children. Crit Care Shock. 2013;16:48-57.

19. Agrawal S, Sachdev A, Gupta D, Chugh K. Platelet counts and outcome in the pediatric intensive care unit. Indian J Crit care Med peerreviewed, Off Publ Indian Soc Crit Care Med. 2008; $12: 102-8$.

20. Fatima I, Shahid G, Ali SS, Bhatti N. C - Reactive Protein as A Predictor of Sepsis in Children Up to 5 Years of Age. 2017;22-6.

21. Sharma R, Sharma J. Original article: Role of C Reactive Protein in Pediatric Sepsis. 2018;5763.

22. Horvat CM, Bell J, Kantawala S, Au AK, Clark RSB, Carcillo JA. C-Reactive Protein and Ferritin Are Associated With Organ Dysfunction and Mortality in Hospitalized Children. Clin Pediatr (Phila). 2019;58:752-60.

23. Lubis $M$, Lubis AD, Nasution BB. The usefulness of c-reactive protein, procalcitonin, and PELOD-2 score as a predictive factor of mortality in sepsis. Indones Biomed J. 2020;12:102-8.

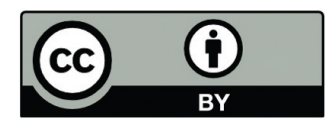

This work is licensed under a Creative Commons Attribution 